
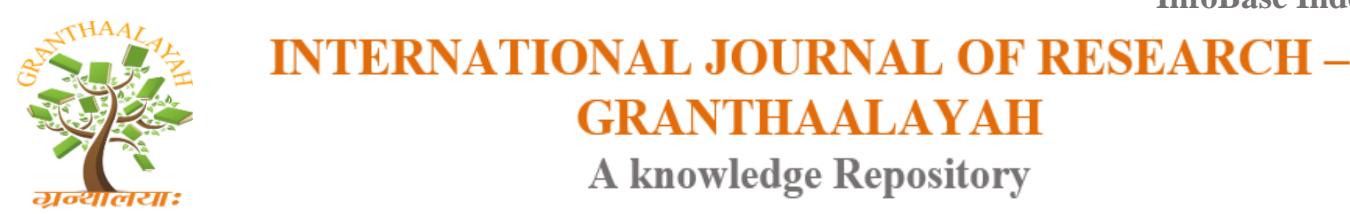

Management

\title{
IS PAKISTAN STOCK MARKET EFFICIENT? (A COMPREHENSIVE STUDY ON PAKISTAN STOCK EXCHANGE)
}

\author{
Muhammad Shaukat Malik ${ }^{* 1}$, Samavia Munir ${ }^{2}$, Noorulain Waheed ${ }^{3}$ \\ ${ }^{*}$ Alflah Institute of Banking and Finance, Bahaudin Zakariya University Multan, Pakistan \\ ${ }^{2,3}$ University of Education, Lahore, Multan Campus, Multan, Pakistan
}

DOI: https://doi.org/10.5281/zenodo.571541

\begin{abstract}
The purpose of this research is to find weak form of market efficiency of Pakistan stock exchange. Daily return of KSE-100 index was obtained during the time period of 2 nd November 1991 to 28th may 2015. Total time span of the study was 23 years 6 month and 26 days. To examine the stationary in the data points three test named as Graphical Analysis, Autocorrelation Function (ACF) and The Unit Root Test were applied. After that ARIMA $(1,1,2)$ model was applied and SPSS 21 used for data analysis. Results revealed that the Pakistan stock exchange not fulfill the necessary assumptions of weak form of market efficiency. Research findings would be beneficial for the individual investors as well as for the businesses as it guide individual investors for establishment of their investment portfolio and for businesses to get funds at appropriate cost. This research is valuable for the researchers as they can explore the current idea of research in other equity investment alternatives of Pakistan and also provide guideline for law regulatory authorities for establishment of laws and regulations of stock markets. This research work would be a valuable addition in the current literature as very few studies have been conducted in emerging stock markets.
\end{abstract}

Keywords: Market Efficiency; Emerging Stock Market; Pakistan Stock Exchange.

Cite This Article: Muhammad Shaukat Malik, Samavia Munir, and Noorulain Waheed. (2017). "IS PAKISTAN STOCK MARKET EFFICIENT? (A COMPREHENSIVE STUDY ON PAKISTAN STOCK EXCHANGE).” International Journal of Research - Granthaalayah, 5(4), 250-262. https://doi.org/10.5281/zenodo.571541.

\section{Introduction}

In the end of $80 \mathrm{~s}$, a small number of institutional investors initiated to consider other than traditional financial markets and started to invest in emerging equity markets. This small group of investors had a very powerful perspective for investing in emerging markets. They believe that they can get benefit from economic growth of these emerging markets if they invest in the equity markets those were at an initial stage of economic development and had significant 
potential for additional development. They predicted that the emerging markets of developing countries would gradually adopt market development strategies in a globalizing world and if they will invest in the stock markets at low valuation as these markets are undiscovered inconsiderable. As a result, from the last twenty years these markets are continuously growing and expanding markets and moving toward appropriate liquidity and size to become very attractive for investors. Also Emerging equity markets have become attractive international investment scenario for providing diversification in security investment. As a result the total volume of international Emerging Market investment and size of international portfolio investment in the equity markets of the developing countries has been increased. MSCI is a emerging market index that was introduced in the year 1988. According to MSCI the participation of emerging market in all country world index (ACWI) has increased from $1 \%$ to $12 \%$ In the end of 2008.

Stock market performs a role of bridge as it enables individual investors as well as institutional investors to increase the nation's wealth through investing in the different securities of the secondary market. Stock market efficiency is based upon the fact in which the price assigning process on a security market is able to assign accurate values to the securities that are listed with security market. Stock market efficiency is important because these value assigning process ensure channeling the savings to their most potential users. In short a stock market is considered to be efficient if it quickly and accurately incorporates all the available information into its stock prices. The rapid adjustment of stock prices upon the arrival of new information ensures that no investor will be able to earn abnormal returns on a market by analyzing the set of information. The reason is that in an efficient market that information is already being incorporated into the listed stock prices.

The efficient market confirms the presence of fair stock prices with no trading cost, all market latest relevant information is freely and costlessly available to all market participants and all the market participants are agreeing to incorporate this information in the stock prices.

Pakistan is a developing country and in the phase of economic development. Common people have no information about how to invest in the stock market so the limited people trade in stocks. Most of the people utilize their savings in different alternatives instead of investing in stock market. In such a situation there is need to promote the concept of market efficiency that will not only help the companies for getting the funds as well as for the investors for best utilization of their savings.

\section{Literature Review}

The stock market is a place where the supply and demand forces for the share of a company determine the market value of that company. The reliable stock valuation process influences the company market value (Potocki \& Swist, 2012).

Another researcher Robinson,(2005) define the concept in a way that in efficient stock market stock prices immediately react on the arrival of new relevant information in exact and accurate fashion. Whereas in inefficient market the information takes time for adjusting in the stock prices 
and investors take time to evaluate the information, that is the reason that stocks sometime over react or under react to that information.

The concept of stock market efficiency becomes more elaborated from Asif, et. al. (2015). They explain a market is considered as efficient in which the price assigning process on a stock market is able to assign accurate relative prices to the listed securities.

Fama (1991) is considered among the pioneer researchers who had initiated his efforts to classify the market efficiency on the basis of classification of available information called past stock price information, all publically available information and all privately available information. According to these classes of information he divides the efficient market into three levels and these levels are Weak form of market efficiency, Semi strong form of market efficiency, and Strong Forms of market Efficiency.

A market is said to be weak-form efficient if current stock prices fully reflects all available information in past stock prices i.e., in efficient market successive stock returns are not dependent of each other (Sultan, et. al., 2013).

A market is said to be semi-strong form of market efficient if current stock prices are adjusted by all publically available information. This publically available information includes information about earnings, stock splits or any other relevant information published in company or country accounts (Ahmad, 2002).

Market is said to be strong form of efficient if current stock prices fully reflect all public and private information, even that information is kept only by insider of the corporation. Thus if the market will strong-form efficient, then no stock will be overvalued and no stock will be undervalued and pay risk adjusted net return (Potocki and Swist, 2012).

Weak form of market efficiency of different stock markets of different countries is examined by different researchers for different time intervals. Zoubi \& Zu'bi (2007) empirically examine the weak form of market efficiency for daily stock return of Amman Stock Exchange (ASE), the results shows that the Amman Stock Exchange (ASE) is inefficient.

Asiri (2008) examine the weak form of efficiency of Bahrain stock market (BSE) and analyze the daily stock prices of all listed companies with BSE for the period from 1 June 1990 up until 31 December 2000. She concluded that all daily stock prices at Bahrain stock market (BSE) fulfill all the assumptions of Random walk with no drift and trend for each sector of the market.

Guidi \& Gupta (2011) analyze the weak form of efficiency of Association of South-East Asian Nations (ASEAN) security markets from 2000 to 2011. They analyze these markets separately as well as in combination. The empirical results show that markets of Indonesia, Malaysia, Philippines and Vietnam are weak form of inefficient while the markets of Singapore and Thailand are weak form efficient.

Market efficiency of African stock markets by analyzing the 32 stock price indices was investigated by Ntim (2011), and he concluded that the stock price indices of all the 24 African 
continent stock markets are less non-normally distributed as compared to the stock indices of the eight individual national stock markets.

Weak form of market efficiency of emerging and industrialized economies are compared by Nwachukwu and Shitta (2015), for this purpose they compare the monthly stock indices of twenty four emerging and nine industrialized economies for the period January 2000 to December 2010. The results show that the stocks listed on emerging stock markets show higher average return with high volatility as compared to those stocks that are listed with stock exchanges of industrial economies.

\section{Research Framework}

\section{Hypothesis Development of Weak Form of Market Efficiency}

According to the empirical study, stock markets of most of the developing countries do not follow the assumptions of the weak form of efficiency i.e., investor can predict the future stock prices by analyzing the historic stock prices. In other words the stock prices not follow the random pattern and past stock prices contain certain information. So on the basis of empirical studies and above discussion a hypothesis can be formulated that is related with the weak form of stock market efficiency of Pakistan.

H1. The current stock prices are based on the past day stock prices i.e. the Pakistani Stock Market does not follows the weak form efficiency in stock prices

\section{Measurement of Variables of Weak Form of Market Efficiency}

Daily data of KSE-100 Index for the period $2^{\text {nd }}$-November 1991 to $28^{\text {th }}$ - May 2015 is taken to examine the weak form of market efficiency. Daily return is calculated as follows.

Daily return $=\ln \mathrm{p}_{\mathrm{t}}-\ln \mathrm{pt}-1$

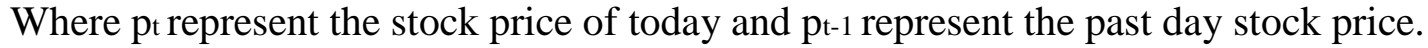

\section{Estimation Techniques Applied for Weak Form of Market Efficiency Analysis}

To examine the market efficiency of Pakistan stock market we apply time series techniques at the KSE-100 index point. For the purpose of time series analysis, we have daily data of KSE-100 index for the period from $2^{\text {nd }}$ November 1991 to $28^{\text {th }}$ May 2015. Firstly we will examine that data is stationary or non-stationary after that we shall try to fit best ARIMA model and best exponential smoothing model .SPSS statistical software will be used to determine the best fitting model. We give comparison between best ARIMA model and best exponential smoothing. After comparison, the most suitable model will be selected for the purpose of forecasting. 


\section{Tests for Stationary}

For time series analysis, first step is to analyze that the data set is stationary or non stationary and for checking stationary, there are three tests named.

1) Graphical Analysis

2) Autocorrelation Function (ACF) and Correlogram

3) The Unit Root Test.

\section{1) Graphical Analysis}

Graphical analysis is a technique used to examine the trend in the time series analysis. The graphical presentation of the data of KSE-100 index points shows that there is consistent upward trend in the data set, which shows that data set may be non-stationarity. Graphical representation of the data set is attached in appendix, fig. A.

\section{2) Autocorrelation Function (ACF) and Correlogram}

The Spikes of Autocorrelation function of KSE-100 index for the period $2^{\text {nd }}$-November 1991 to $28^{\text {th }}$-May 2015 are mostly out of limits which also confirm that variables of study are nonstationarity/non randomness in the returns as shown in appendix fig. B.

\section{3) Unit Root Test /Augmented Dickey-Fuller Test (ADF)}

Augmented Dickey-Fuller test (ADF) is the type of unit root test that is used in statistics and econometrics that is an augmented version of the Dickey-Fuller test used to examines the unit root in the time series data. Augmented Dickey-Fuller test (ADF) is the test that is applicable on the large and complex time series data. Maximum negative value of Augmented Dickey-Fuller test statistics is the stronger evidence of rejection of the study hypothesis and the presence of unit root between confidence interval.

The ADF test statistics of the present study fall in the acceptance region for all confidence intervals including 99\%, 95\% and 90\% that confirms the presence of unit root and the results are attaches in appendix of table a. Hence we conclude that variable of present study is not stationary and continuously increasing. As there is continuously increasing trend in the values of KSE-100 index point, hence the future stock prices can be predicted that reject the presence of efficiency in the Pakistan stock market.

From all the above three techniques applied on the data set KSE-100 index points conclude that the present data is nonstationary and to make data set stationary we will use the "first difference technique".

\section{First Difference Techniques}

To make the data set stationary, the first difference technique is used. Further the three tests would be applied to check the stationary or nonstationary position of data set after first difference has been applied and these tests are as follows. 
1) Graphical Analysis after first difference

2) Autocorrelation Function (ACF) and Correlogram after first difference

3) Unit Root Test after first difference

\section{1) Graphical Analysis after First Difference}

The graphical presentation of the KSE-100 index points clearly shows that there is no consistent upward trend in the data set after first difference that confirms that data set of the present study is stationary. The graphical presentations of the KSE-100 index point after first difference are attached in the appendices fig. D.

\section{2) Autocorrelation Function (ACF) and Correlogram after First Difference}

Autocorrelation Function (ACF) and Correlogram after first difference on the data set has been applied and the results conforms that only four spikes lies above the upper confidence limit, Also only three spikes of data set of partial Autocorrelation Function fall outside the upper confidence limit, results are attached in the appendices of Fig. E and F. As the more spikes close to zero confirms the presence of stationary position in the data set.

\section{3) Unit Root Test /Augmented Dickey-Fuller Test (ADF) after First Difference}

Results of Unit Root Test /augmented Dickey-Fuller test (ADF) after first difference shows that ADF test statistic falls in the rejection region results are attached in appendix table b. So we will reject null hypothesis (data is not stationary) and accept alternative hypothesis (data is stationary). Hence it is clear from all three above tests that the variables of present study are stationary at first difference.

\section{ARIMA Model}

After making data is stationary, next step is to find out best ARIMA $(p, d, q)$ model. In this part, the ARIMA (p, d, q) technique is applied on the daily KSE-100 index points to find out best $\operatorname{ARIMA}(p, d, q)$ model.

\section{1) Selection of the Parameters}

In the procedure of ARIMA $(p, d, q)$, first step is choosing the parameters of the ARIMA ( $p, d$, $q)$ model. ACF plot is used for identifying order of $\{p\}$ and PACF plot for identifying the order of $\{q\}$. Above results clearly shows that ACF appear four significance spikes, PACF appear three significance spikes.

\section{2) Model Selection}

After deciding parameter values, next we shall be used different ARIMA $(p, d, q)$ models in order to find out, the best model for data of daily number of index point. Different models with fitted criterion are given in the following table. 
Table 1: Normalized BIC, MAPE and Stationary $\mathrm{R}^{2}$ values of ARIMA models

\begin{tabular}{llll}
\hline Models & MAPE & Normalized BIC & Stationary $\mathrm{R}^{2}$ \\
\hline ARIMA $(1,1,1)+\mathrm{C}$ & 1.052 & 9.534 & 0.015 \\
ARIMA $(2,1,1)+\mathrm{C}$ & 1.053 & 9.549 & 0.021 \\
ARIMA $(1,1,2)+\mathrm{C}$ & 1.031 & 9.550 & 0.022 \\
ARIMA $(0,1,2)+\mathrm{C}$ & 1.050 & 9.549 & 0.017 \\
ARIMA $(1,1,2)+\mathrm{C}$ & 1.053 & 9.549 & 0.021 \\
ARIMA $(1,1,0)+\mathrm{C}$ & 1.051 & 9.548 & 0.016 \\
\hline
\end{tabular}

From Table 5.1, it is clear that ARIMA $(1,1,2)$ with constant is best model because it has lowest MAPE and highest Stationary $\mathrm{R}^{2}$.

\section{3) Estimation of Parameters}

Table 2: Model parameters of ARIMA $(2,0,2)+\mathrm{C}$ model

\begin{tabular}{lllll}
\hline Variables & Estimate & SE & T & P Values \\
\hline Constant & 0.001 & 0.000 & 2.052 & 0.040 \\
AR Lag1 & 0.888 & 0.038 & 23.369 & 0.000 \\
\multicolumn{1}{l}{ Difference } & 1 & & & \\
MA Lag 1 & 0.769 & 0.041 & 18.931 & 0.000 \\
$\quad$ Lag 2 & 0.064 & 0.016 & 3.898 & 0.000 \\
\hline
\end{tabular}

Table 2 shows that constant and all lags are significant that is good indicator for our selected model. This model shows that very interesting relation between SE and T one is increase and other is decrease. So we can say that there is inverse relation between SE and T.

\section{4) Diagnostic of Model}

In order to checking the diagnosis of the model, there are some tests and procedures like correlograms of ACF and PACF that are applied to the residuals of the model. We apply them to the $\operatorname{ARIMA}(1,1,2)+\mathrm{C}$.

All spikes of ACF and PACF lie within the confidence band and most of the spikes close to zero. It is good sign for our selected model and it is suggested that there were no significant autocorrelation between residuals at different lag times and the residuals are fellow white noise, process results are attached in the appendices fig. no. G.

\section{5) Fitted Model}

Fig. $\mathrm{H}$ from appendices of figures, it is clear that the (observed) actual values and the predicted (fitted) model values about number of index point matched reasonably well and fitted value plot follow the plot of actual values results are attached in the appendices. 


\section{6) Forecasting Model}

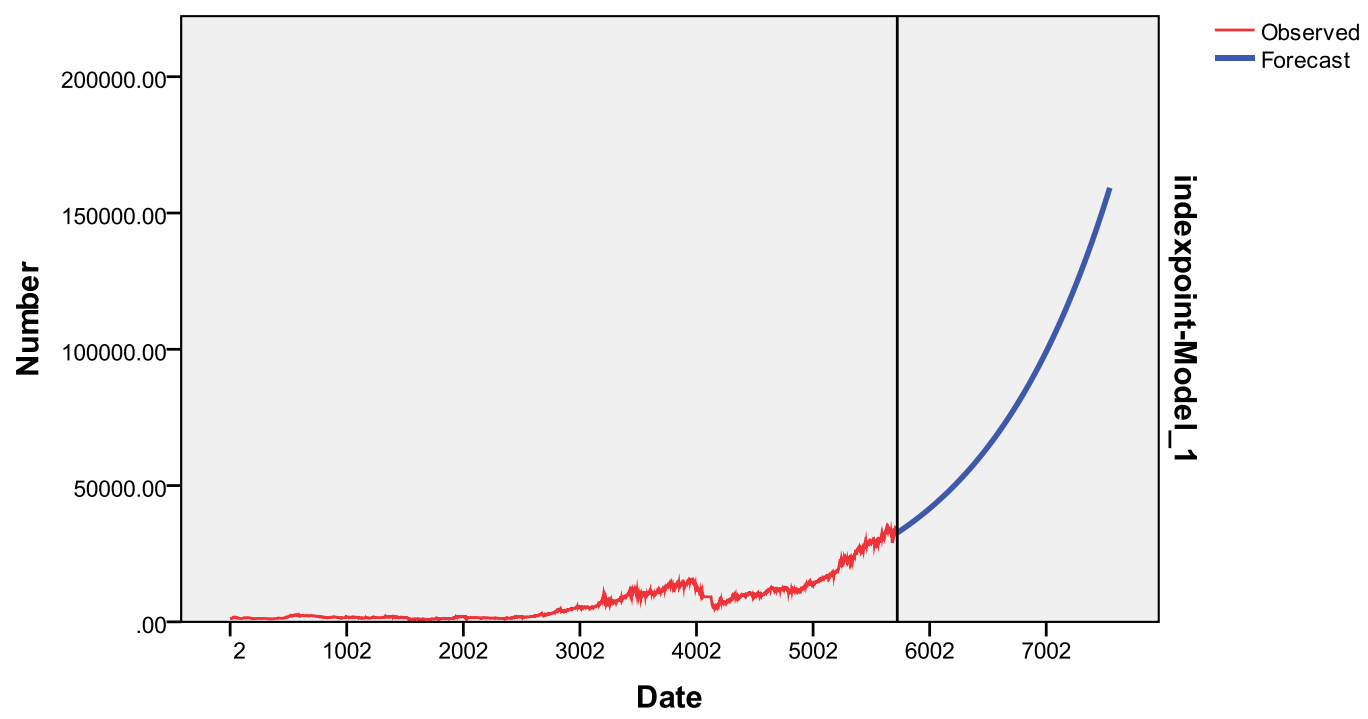

Figure 1: Sequence plots of actual and forecasting values for number of index point

Fig. 1 clearly show that actual values of daily data and forecast values of KSE-100 index for the next five years that consists upon 1825 total number of observations using $\operatorname{ARIMA}(1,1,2)+C$. It is concluded that the forecasting values has the same pattern as the actual values and showing up word trend.

The results shows that the future five year values can be predicted by using the past data of KSE100 index that confirms that the future value of KSE-100 index is predictable and the historic prices provide some signal for future values that is contradiction of weak form of market efficiency. Hence it is concluded that the Pakistan stock market is not weak form of market efficient so the hypothesis $\mathbf{H 1}$ is accepted.

\section{Conclusion and Implications}

The present study is anticipated to examine the weak form of efficiency of Pakistan stock market. Three tests named as graphical presentation, Autocorrelation Function (ACF), Augmented Dickey-Fuller test (ADF) test were applied to monitor the stationary in the data points of return from investment in KSE-100 index for the period of $2^{\text {nd }}$-November-1991 to $28^{\text {th }}$ May-2015. To make the data set stationary these three tests were applied after first difference. After making the data set stationary best $\operatorname{ARIMA}(1,1,2)$ were applied. With reference to above mentioned facts based upon the empirical evidence it is concluded that the stock market of Pakistan does not fulfill all the necessary assumption of market efficiency.

The finding of the present study can provide a step toward the economic development of the country. If the market will be efficient then it will not only attract the domestic investors but also the foreign investors by increasing their confidence in Pakistan stock market so when there will be easily availability of funds that will improve the performance of companies to participate toward economic development. 


\section{References}

[1] Ahmed, F., (2002). Market efficiency in emerging stock markets: The case of Dhaka stock (DSE). Savings and Development, Vol. 26 pp. 49-68.

[2] Asif, M et. al (2015). Testing the weak form efficiency of KSE 100 Index, City University Research Journal Volume 05 Number 02 pp. 291-300

[3] Asiri, B., (2008). Testing weak-form efficiency in the Bahrain stock market, International Journal of Emerging Markets Vol. 3 No. 1, 2008 pp. 38-53

[4] Fama, E. F. (1991). "Efficient Capital Markets." The Journal of Finance, 46(5), pp.1575-1617.

[5] Guidi, F., \& Gupta, R. (2011). Are ASEAN stock market efficient? Evidence from univariate and multivariate variance ratio tests. [Discussion Papers in Finance].

[6] Ntim, C.G., et.al (2011), Testing the weak-form efficiency in African stock markets, Managerial Finance Vol. 37 No. 3, 2011 pp. 195-218

[7] Nwachukwu, J. C. and Shitta, O.,(2015) Testing the weak-form efficiency of stock markets A comparative study of emerging and industrialised economies, International Journal of Emerging Markets Vol. 10 No. 3, 2015 pp. 409-426

[8] Potocki, T \& Swist, T. (2012) Empirical test of the strong form efficiency of the Warsaw stock exchange: The analysis of Wig 20 Index shares, South-Eastern Europe Journal of Economics Vol.2, pp.155-172.

[9] Robinson, J. (2005) .Stock price behavior in emerging markets: test for weak form market efficiency on the Jamaica stock exchange. pp.51-6

[10] Sultan, K. et al (2013) Comparison between Kuwait and Pakistan Stock Exchange Market: Testing Weak Form of Efficient Market. Academy of Contemporary Research Journal, V II (II), pp. 59-70.

[11] Zoubi,H,A.,\& Zu'bi,B.K. (2007), Market efficiency, time-varying volatility and the asymmetric effect in Amman stock exchange. Managerial Finance Vol. 33 No. 7, 2007 pp. 490-49

*Corresponding author.

E-mail address: samaviasb@gmail.com

\section{Appendix (Figures)}

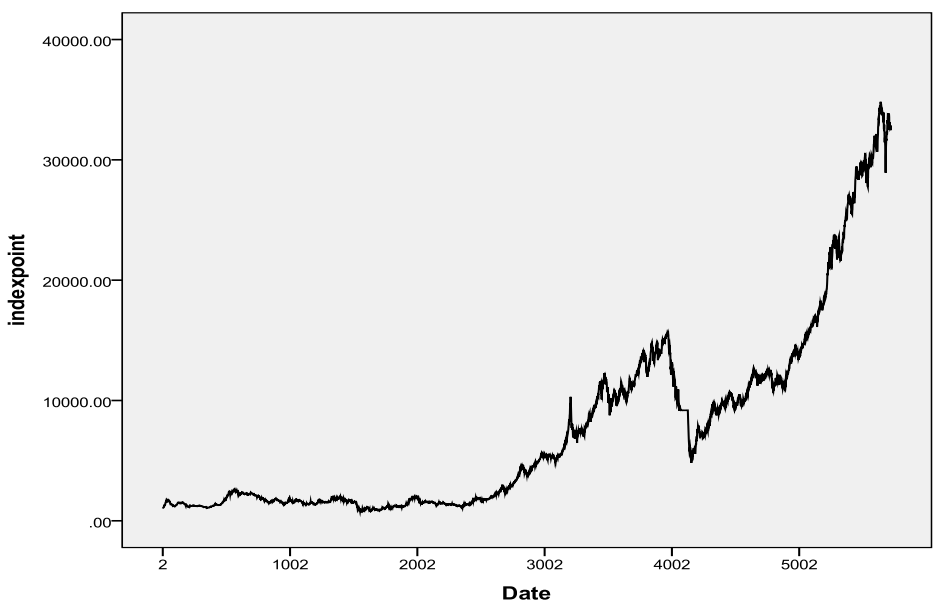

Figure A: Sequence plot of total number of Index point. 


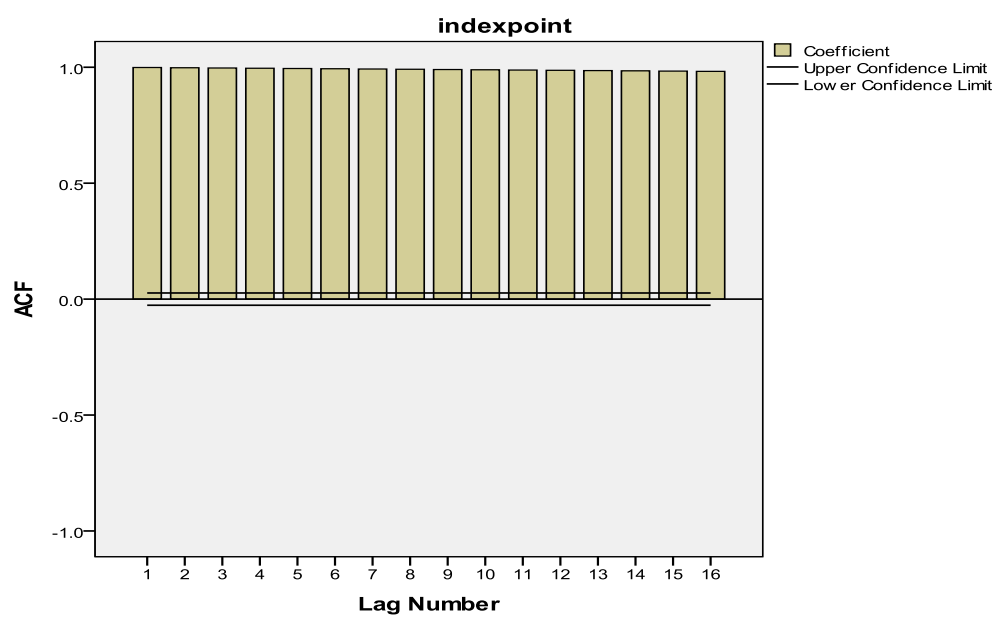

Figure B: Autocorrelation Function for total number of index point

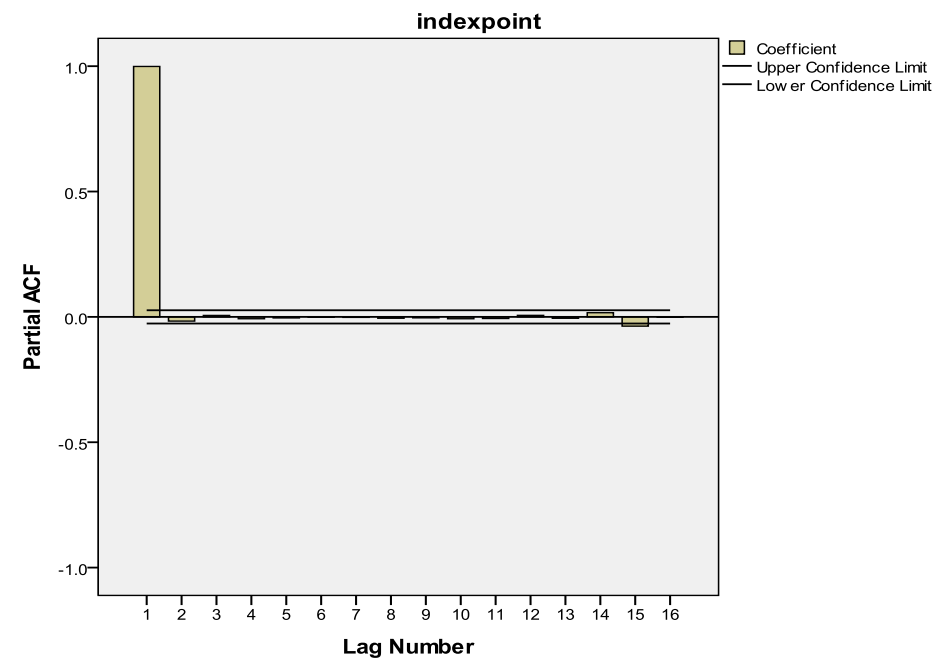

Figure C: Partial Autocorrelation Function for total number of index point

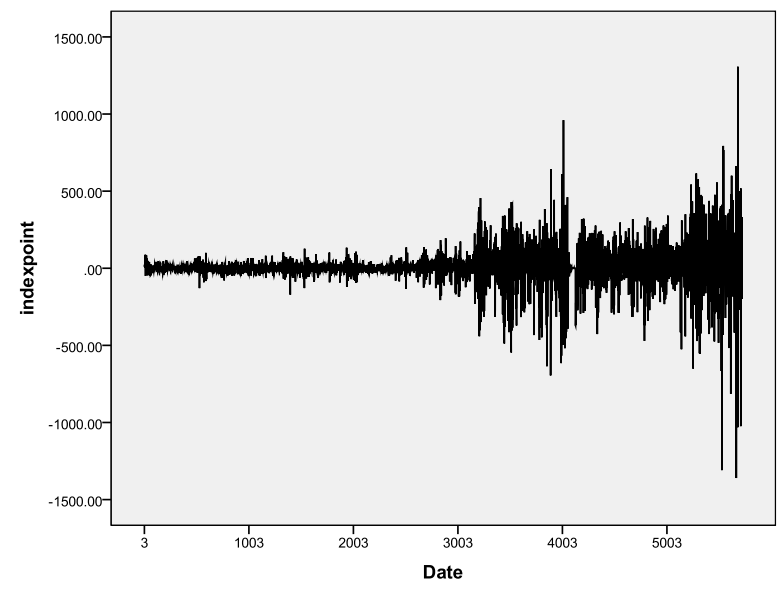

Transforms: difference(1)

Figure D: Sequence plot of total number of Index point after first difference 


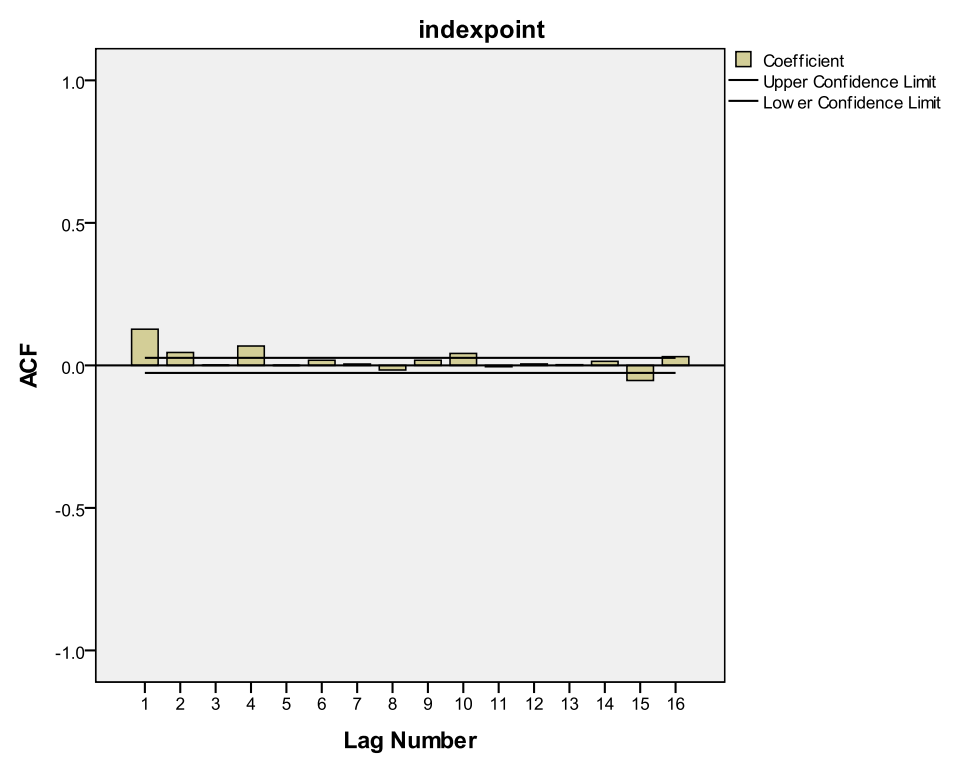

Figure E: Autocorrelation Function after first difference

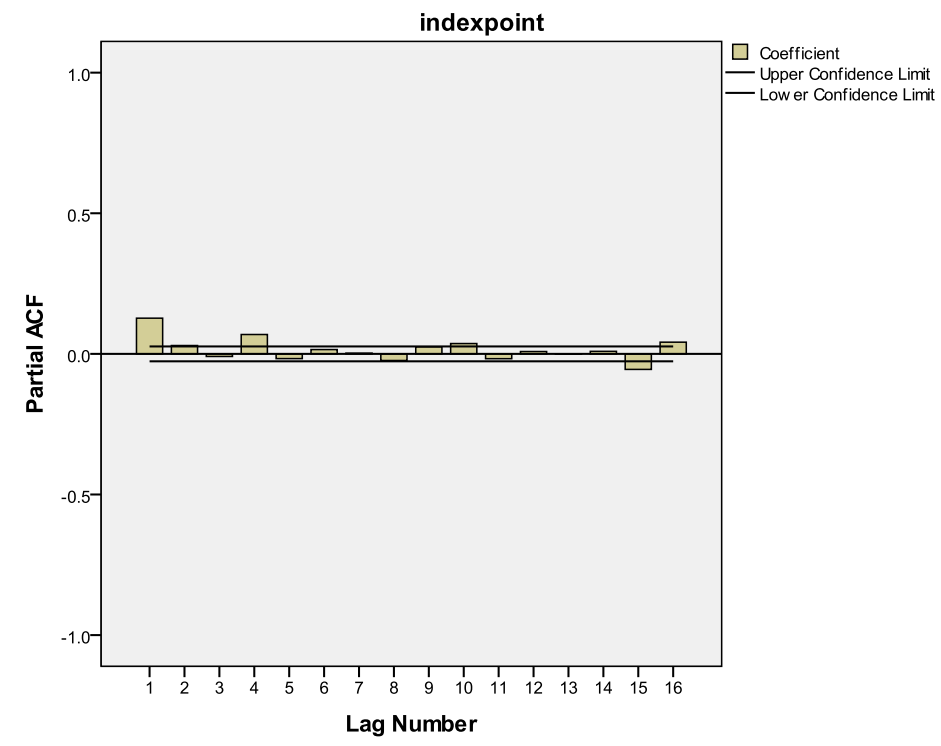

Figure F: Partial Autocorrelation Function after first difference 


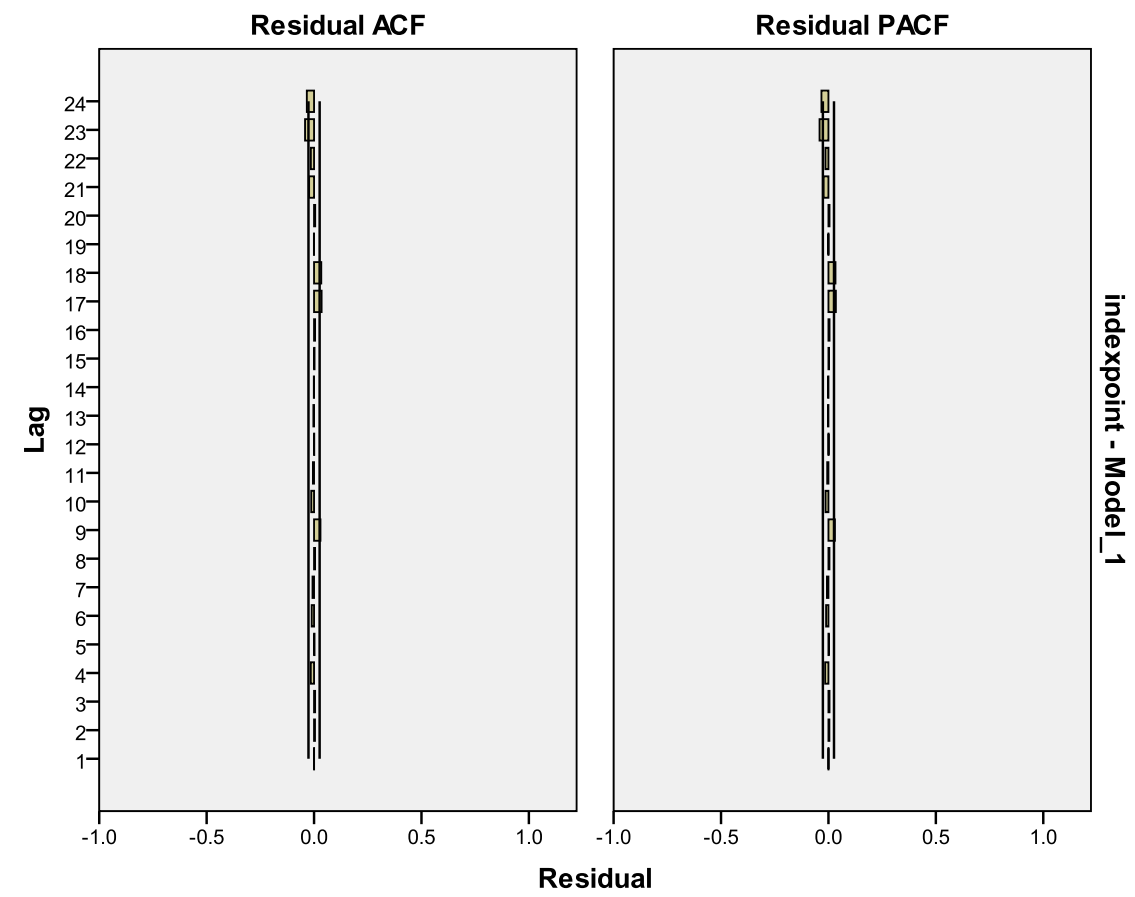

Figure G: Residual plots of ACF and PACF of ARIMA $(1,1,2)+C$

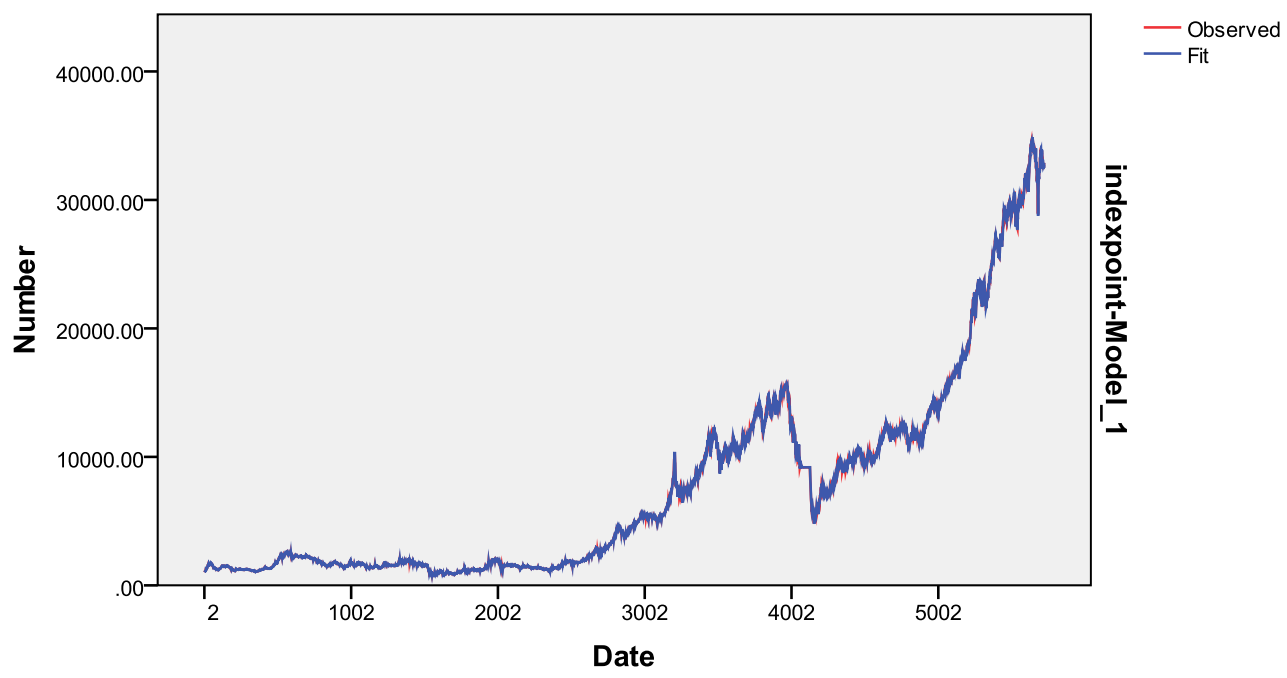

Figure H: Actual (observed) and predicted (fit) plot for index point. 


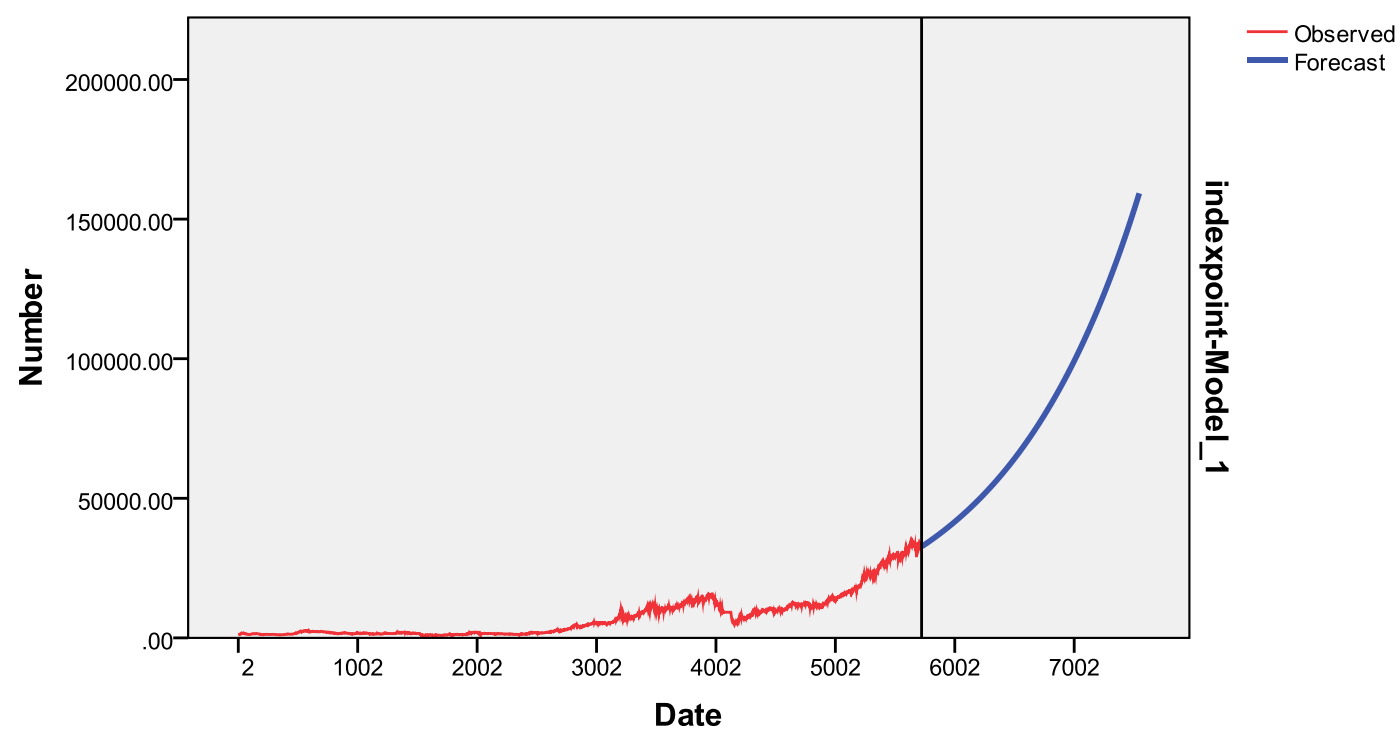

Figure I: Sequence plots of actual and forecasting values for number of index point

\section{Appendix (Tables)}

Table A: ADF Unit Root Test for index point.

\begin{tabular}{llll}
\hline & \multicolumn{3}{c}{ Critical values } \\
\hline ADF test statistics & 3.561 & $1 \%$ & -3.524 \\
& & $5 \%$ & -2.863 \\
& $10 \%$ & -2.567 \\
\hline
\end{tabular}

Table b: ADF Unit Root Test for first difference for index point.

\begin{tabular}{llll}
\hline & & \multicolumn{3}{c}{ Critical values } \\
\hline ADF test statistics & -66.551 & $1 \%$ & -3.43 \\
& & $5 \%$ & -2.86 \\
& $10 \%$ & -2.56 \\
\hline
\end{tabular}

